\title{
Digital Revolutions Affecting Distribution Within the Games Sector
}

\author{
Malte Behrmann \\ bbw Hochschule, Berlin, Germany
}

\begin{abstract}
The paper addresses the two main revolutions the games industry underwent within the last decade in its distribution structures: The internet shift and the mobile revolution. The author observes and describes economic phenomena which he has witnessed in many workshops and interviews within several EU research projects. By modeling different scenarios of actors in the ecosystem he now shows that the structures have seen dramatic changes and shifting opportunities for all market participants. As a result, he shows that both revolutions have opened opportunities for fast movers, but over time those opportunities have been shrinking with more and more actors coming on board.
\end{abstract}

Keywords: digital shift, games industry, online revolution, mobile shift, mobile games

\section{Introduction}

When the French Revolution broke out in 1789, Talleyrand-Perigord (1891), writing in his memoirs, recalled how the Duke of La Rochefoucauld informed King Louis XVI of the precarious situation:

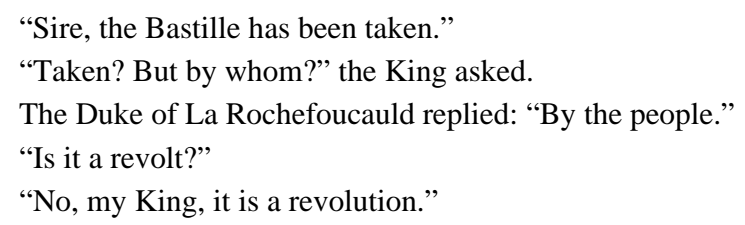

If examined in more detail, the revolution that subsequently swept through France was comprised of a series of upheavals — similar to the revolution that erupted in Russia well over a century later. In the case of the French, the first revolution was that of the Jacobins, who were later deposed by other less radical forces. Over the course of the following decade, this revolution in turn gave way to the Napoleonic era. The Russian revolution also involved several revolts occurring at different flashpoints throughout the year of 1917 (Bracher, 1983, p. 38).

A similar process of "multiple" revolutions within the digital revolution has been affecting the global media industry over the past 20 years - namely in the form of an internet and a mobile revolution. The music industry was the first to feel its impact with the arrival of Napster portal (Renner, 2004, p. 153). Then it was the film industry's turn, followed by the computer game industry. Print is the latest sector to feel the digital

Malte Behrmann, professor, Creative Industry Managament and Communication, bbw Hochschule, Berlin, Germany.

Correspondence concerning this article should be addressed to Malte Behrmann, bbw Hochschule, Leibnizstraße 11-13, Berlin 10625, Germany. 
“scourge” (Beyer \& Carl, 2012, p. 83).

This paper will focus on the revolutions affecting the gaming sector, since game developers are a unique case when it comes to digitization: To be successful, they must be imaginative as well as technically and commercially astute. The development of business models within the games industry is therefore a very good point to commence a more detailed analysis of what the global media world is currently experiencing as a result of the revolutionizing process of digitization. And to begin the analysis, we must firstly understand that the history of the digital revolutions which can be divided into three acts.

\section{First Act}

Before the PC gaming distribution process became digitized, computer games were predominantly produced as CDs, packaged into boxes, and finally sold in stores. Although this still occurs to some extent today, it is to nowhere near the degree it was 15 years ago.

The developer was not unlike the author at that time, in that they developed a project they then presented to publishers, usually in the form of a prototype or demo produced at their own expense. Developers typically had at this point very few resources of their own. As such, they were often all too ready to sign any contract put before them. The game publisher, if it deemed the game had merit, then funded its completion and brought the game to market. The business model at play here is also similar to the music industry, in that it is based on an advance that is later recouped through eventual sales.

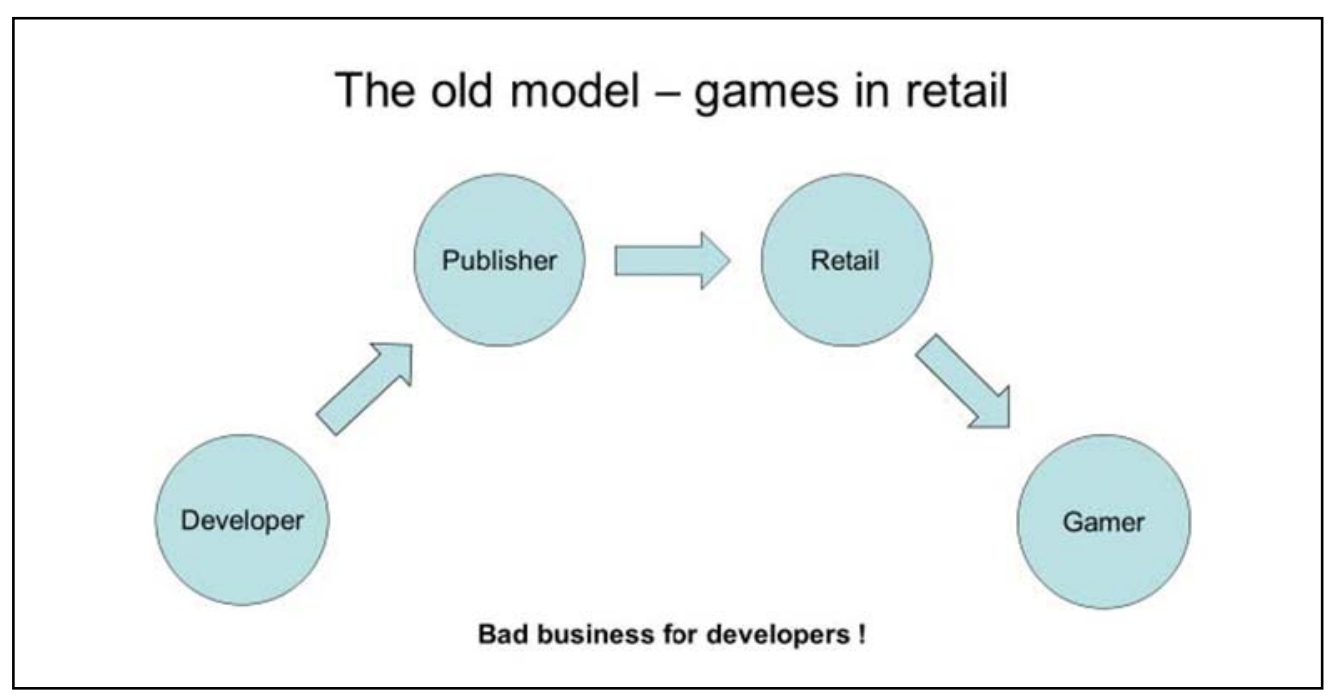

Figure 1. The old model—games in retail. Source: Own illustration.

Caves (2000, p. 57) describes the "Advance against Royalties" arrangement for the music industry. It allows computer game publishers to retain further royalty payments until their advance has been recouped. If the game is not particularly successful, the developer receives nothing more than their advance. As a result, advances are often the only payment a developer ever receives for the game they developed.

This phase was firmly rooted in the period of analogue economics when it was advantageous to maintain large distribution structures. The most expensive part of the computer game publishing process at that time was managing and paying a small army of salespeople who, as representatives, drove from business to business to ensure the games reached the shelves. 


\section{Second Act}

Digitization began to affect the distribution of computer games from the middle of the first decade of the new millennium, when it suddenly became possible to download games over the Internet. The new generation of gamers now registered online. Technically this was already possible, and small groups of gamers had previously received their games in this fashion. But in the broader sense, the concept of online computer games was a novelty. During the first dotcom boom, Moorhuhn could establish itself here in Germany as an online game. Then the bubble burst, and the market shifted dramatically.

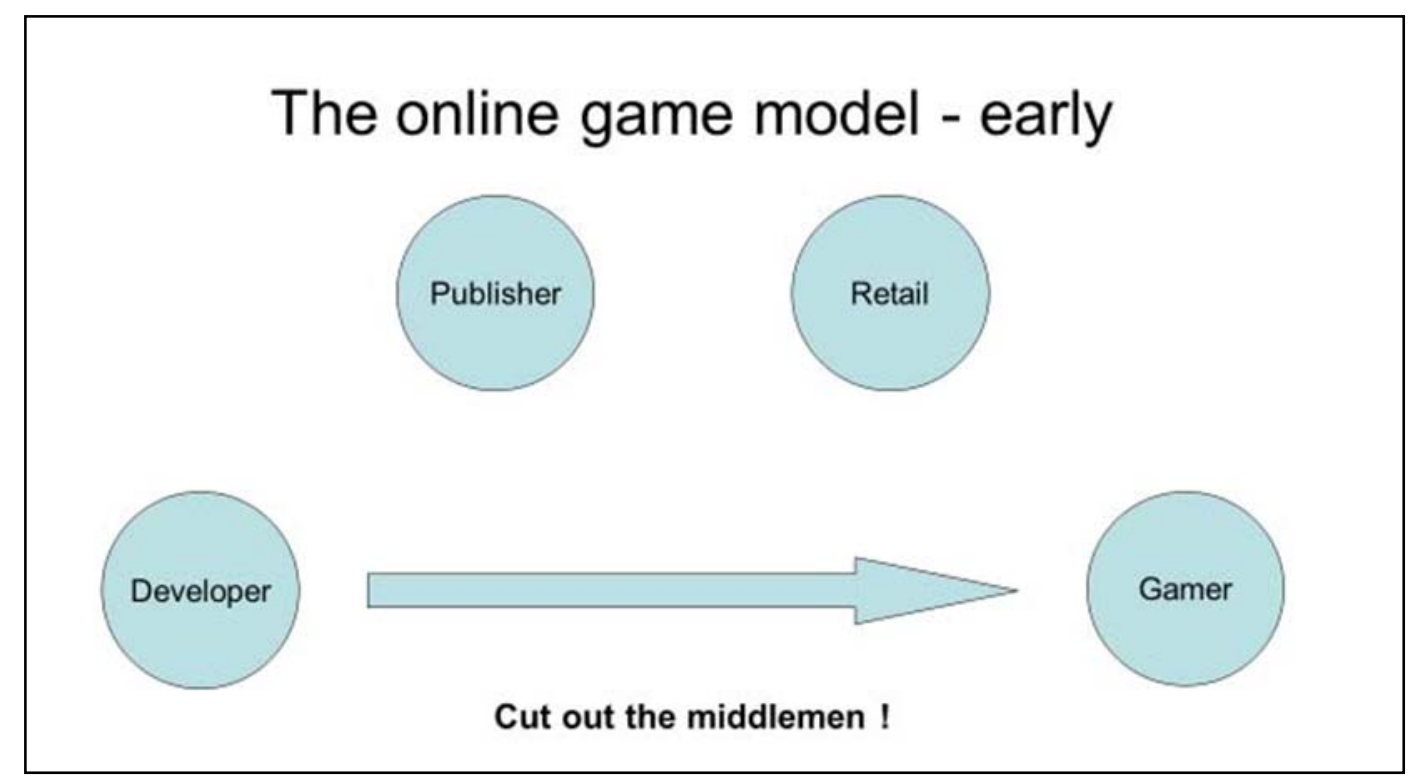

Figure 2. The online game model—early. Source: Own illustration.

To understand this upheaval more precisely, one must accept that technical innovation alone is not necessarily the decisive trigger for digitization, rather that the behavior of the mass market can be considered an independent phenomenon. When and why users suddenly decided to go online cannot be predicted. And that decision does not depend solely on the technical prerequisites either. A contextual relationship can already come into being because of the possibility of substitution, in that it becomes possible to replace one solution with something better-in this case then the new possibility to play with and against other people online. Of course, economic factors are of great importance from the point of view of users too, in that they will generally choose the much cheaper option-legal or illegal.

When considering the factors that led to online games gaining mass market appeal within Germany, we cannot ignore the psychological phenomenon (Ferrari, Lessiter, Freeman, \& Dumbreck, 2010) of browser games. At first, it was only a small community of German developers who produced computer games playable directly in the browser without the need to download a control program. The great advantage of this design was that you could play games online without leaving data traces (particularly useful if the games were played at work) or inadvertently installing a virus. The entry threshold for the players was also much lower. These factors, among others, contributed to the growth of browser games particularly in Germany, where users are generally considered to be more conservative concerning their fear of viruses and monitoring at the workplace.

Browser games experienced their real breakthrough in 2006 when the firm Bigpoint and the television 
channel SAT1 concluded a revenue share deal related to the FIFA World Cup. The arrangement saw all non-allocated advertising spots being allocated to Bigpoint, with revenues being shared between the two partners as result. There are many such spots on a private station when the World Cup is taking place in a country within public television. Following the World Cup, Bigpoint reached several million users for the first time. Between 2006 and 2010, Bigpoint and its main competitor Gameforge assumed a global user base that exceeded several hundred million users. These were the golden days.

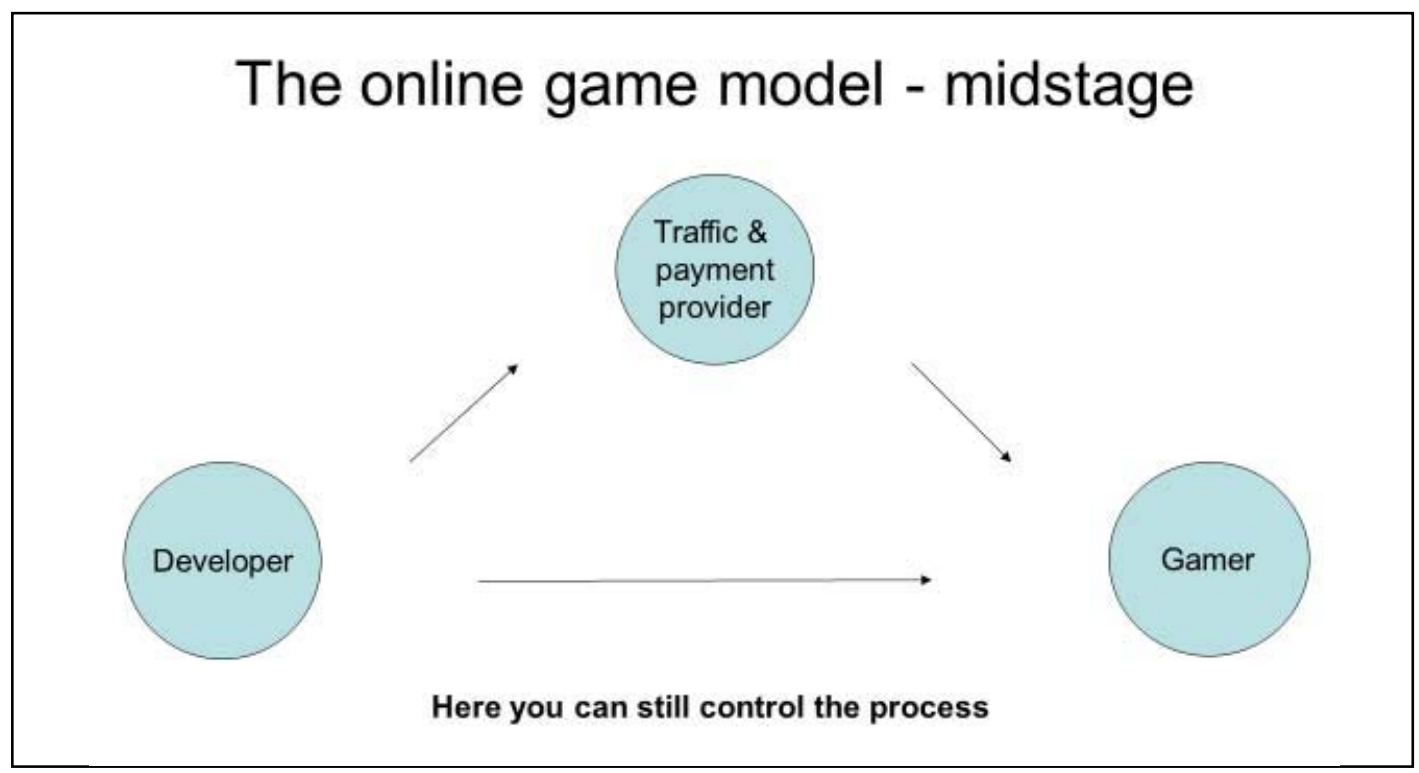

Figure 3. The online game model—midstage. Source: Own illustration.

It is important to note that the real advantage for computer game companies was that they could communicate directly with the end user - a contact that guaranteed data sovereignty. This period also saw the transition from classic retail to online retail around the world.

In 2008 the distribution structure shifted entirely. The new model, in which the game developer had direct contact with the user, became more and more relevant. Computer games themselves also changed significantly through this new business model (Schultheiss, 2007). The game experiences shifted from being principally narrative structures to participatory virtual worlds. There was the possibility that several players could play together in the same game at the same time. Competition was no longer with the machine but held virtually against other real players. Multiplayer versions also have the effect that the real world is being extended around a virtual one.

The new business model (Wi, 2009, p. 33) was called Free to Play (Alha, Koskinen, Paavilainen, Hamari, \& Kinnunen 2014). It was created based on the popular Follow the Free strategy (Beyer \& Carl, 2012, p. 222). Since this development, computer games have been offered initially freedom on the Internet. During the game, additional virtual items (Rauda, 2013) or other game advantages are offered at certain points which can be purchased for real money. Only about $1 \%-5 \%$ of players use this opportunity, while the remaining $95 \%-99 \%$ play on for free. This development also changed the content of computer games. Now developers are having to design worlds where they could request money in specific places. This model was developed in South Korea and then implemented in other parts of the Western world (especially in the USA), with Germany seeing a quicker uptake of the concept than elsewhere. For me, this development was a clear indication that Europeans 
should work more closely with East Asians. We can only learn. On the other hand, East Asian gaming firms should cease to attach their European offices to a US Headquarter. Europe is a significant market and location. One main criticism of digitization is that one should traditionally be able to distinguish between the real and the virtual world. In my opinion, this distinction is a major misunderstanding. The real world is expanded around the virtual world. We continue to live in a world containing real and virtual elements.

Another important factor in this development is that of the corresponding evolution in the online advertising industry. For many years, it has been possible to advertise computer games online in other computer gaming portals via banner ads. Online gamers are continually visiting new websites because of this process. This has seen a rise in the number of agencies that place advertising banners to motivate players to register themselves in new games. From the agency's point of view, you could argue that they assume the risk of generating new players by running ads until users have responded to them. In other words, players can be "bought" in the realm of online gaming.

This "player trading" has seen the advertising industry assuming a highly influential role, as it is in this space that the commercial success of a computer game can be measured: if you can buy users and the reproduction of the product is free, then logically you can generate higher margins by generating more users. The key point is to ensure that every paying user statistically spends more money than the user acquisition cost. We are talking about conversion here. In time, the number of so-called traffic and payment providers rose worldwide, and Germany lost its pre-eminence.

\section{Third Act}

After the year 2008 we then saw the market moving in a direction few had predicted: the mobile revolution had begun. What is often forgotten when discussing digitization today is that over the past ten years, two very different revolutions have occurred: first, the digitalization of distribution over the Internet, and then the shift to mobile platforms. In the old days, mobile developers had a hard time surviving in the ecosystem. They were depending on telephone operators who took control over the market and took high margins.

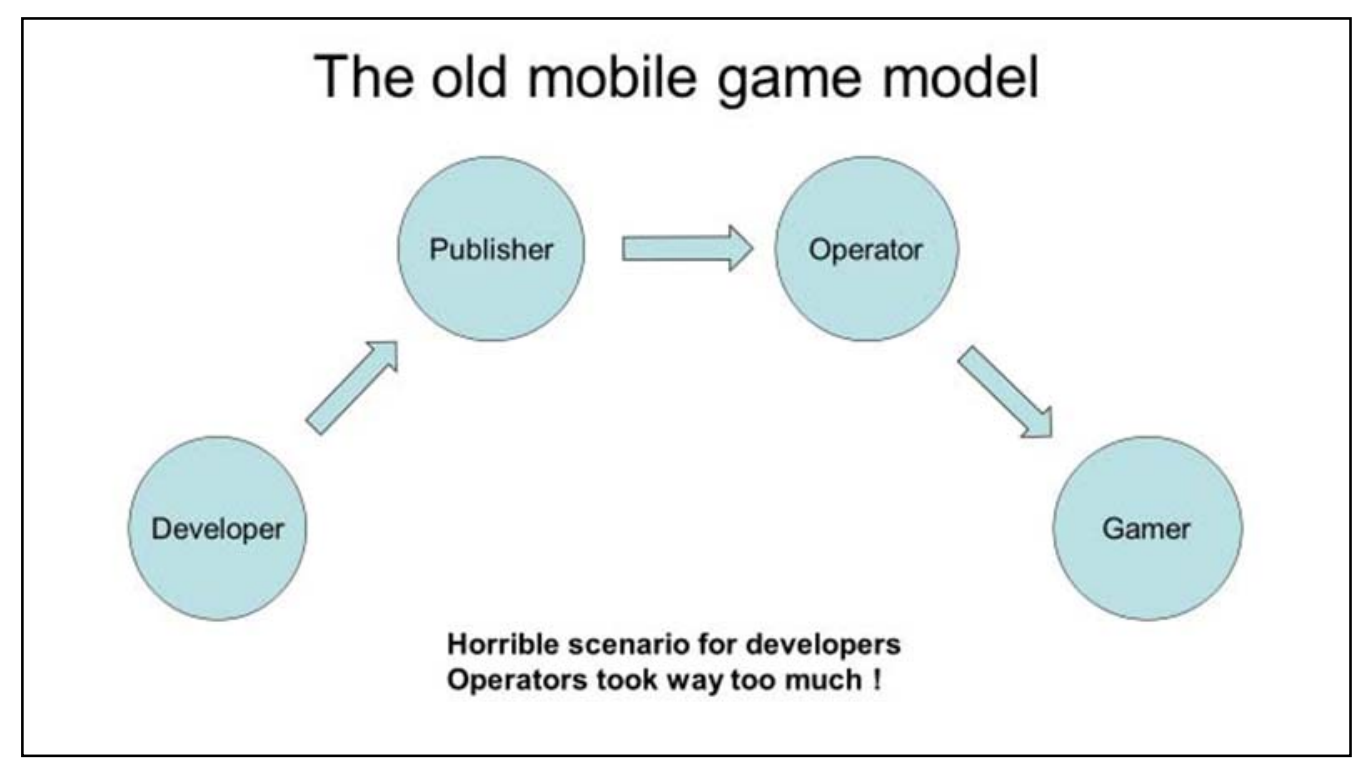

Figure 4. The old mobile game model. Source: Own illustration.

The new mobile platform business model was a positive development from the perspective of computer 
game developers. Even before the mobile revolution, some computer game developers had attempted to make games for mobile phones. But telecom companies had a monopoly over the distribution of such games. They could only be downloaded from the portals of the operators, i.e. Deutsche Telekom, Orange, or Vodafone etc. And the telecoms did not give the content producers great margins. In principle, they had kept more than half of the cake, and game developers were then forced to assume the risk of an entire production with often less than a quarter of the revenue to be expected in return. It was little wonder that many developers of mobile phone games went bankrupt before the launch of the iPhone.

The iPhone brought about further fundamental changes. It was suddenly possible to download computer games via the App Store without interacting with other actors, especially the operators (Behrmann, Point, Noyons, \& Robertson, 2013, p. 4). Here, too, the agent was cut out. Just as brick and mortar retailers had previously been affected by the online development, now it was the telecommunication companies that suffered: They were excluded from the value chain (Behrmann et al., 2013, p. 6).

For the most part, the mobile development went largely unchartered among German gaming firms. From a European perspective, Finland became particularly relevant to this segment. Stars like Rovio and Supercell shot to prominence with games played worldwide. This rise was certainly because a lot of mobile know-how exists in the Nordic countries, and that the economic system is geared towards it, since everyday use of the mobile phones is more widespread than in Germany.

\section{The I-Phone mobile game model}

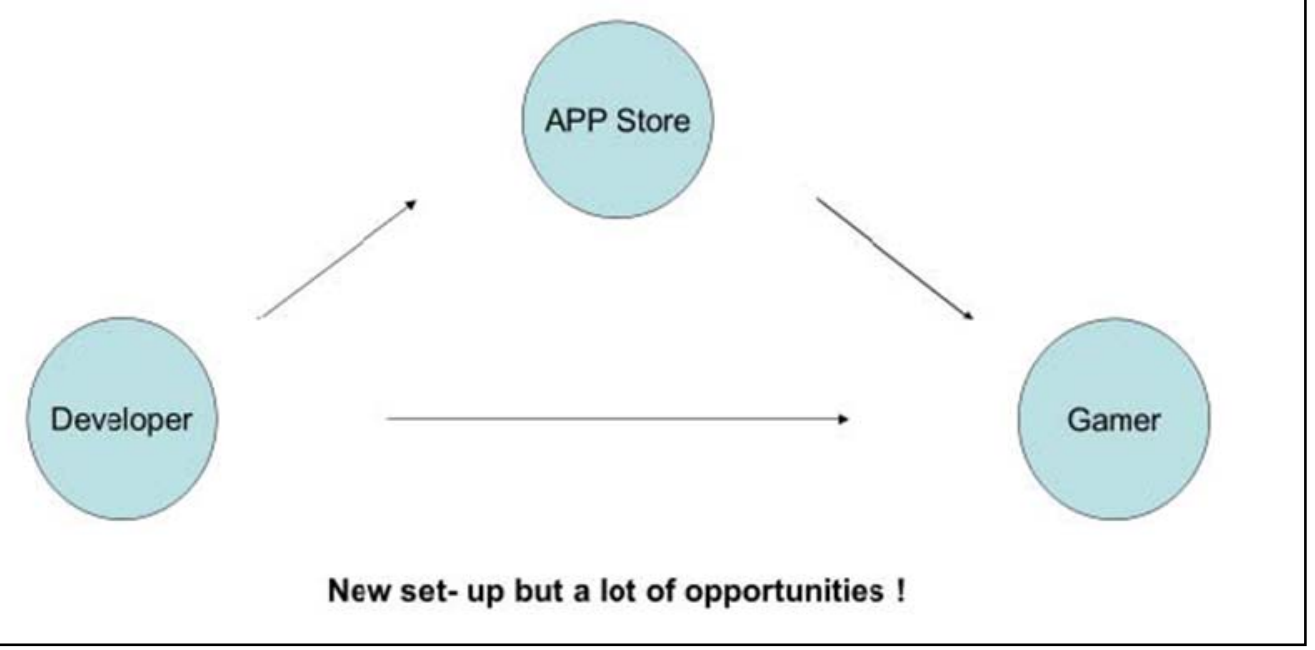

Figure 5. The iPhone mobile game model. Source: Own illustration.

After the mobile revolution, the App Stores took control. Apple’s App Store does not allow third-party providers onto the platform, and prioritizes internal rating systems. Ironically, the closed system of Apple is better for the back-office structure of the content developer: With Android, traffic and payment providers are permitted onto the platform, who in turn can earn a commission on sale. The result is that developers can rely more on Apple's direct payments (App Annie Intellegence cited in Behrmann et al., 2013, p. 13). This makes it possible to make money as a content provider because of the closed end-to-end structure, albeit at relatively strange conditions. The author will never forget a conversation he heard in 2010 between two mobile game 
developers. The one said to another: “Apple is a strange shop. They've paid us $\$ 9$ million in royalties, but we do not know anyone there-just the general, non-personalized email address for developer contacts.”

\section{The mobile game model - now}

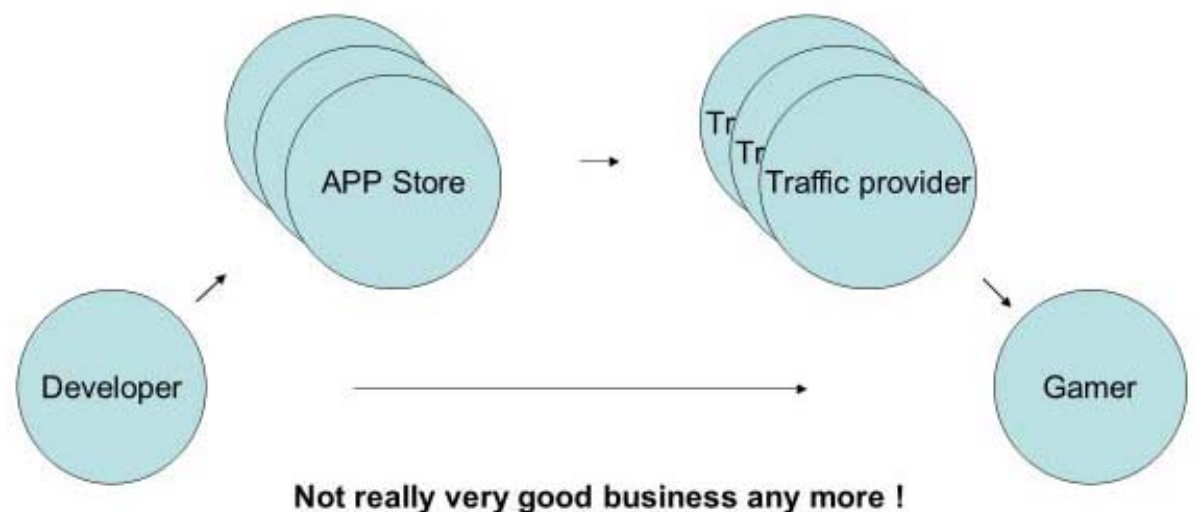

Figure 6. The mobile game model—now. Source: Own illustration.

In Google Play's open platform approach, the chance of external influence is much stronger. Here, as in the online arena, there is greater ability for traffic and payment providers to earn revenue. Game developers therefore usually earn less on Google Play for the same app on Apple's App Store. In the mobile sector, we are currently being confronted with similar issues that affected the online realm in the past.

In this paper, we have examined the two revolutions which have characterized the changes in the distribution structures of computer games within the last decade. We found that we must deal with more than one revolution, more specifically the internet and the mobile revolution. We also found, that other players such as traffic and payment providers play an increasing role within the ecosystems.

\section{Conclusion}

There is not only one digital revolution, but several. In addition to the Internet revolution, the mobile revolution has happened in the games business. It is hard to predict, when the digital shift hits. We observe different principles. These different principles lead to different behavior in the online and mobile space. We can see that both revolutions have opened opportunities for fast movers, but over time those opportunities have been shrinking with more and more actors coming on board.

\section{References}

Alha, K., Koskinen, E., Paavilainen, J., Hamari, J., \& Kinnunen, J. (2014). Free-to-play games: Professionals’ perspectives. Proceedings of Nordic

DiGRA

2014. http://www.digra.org/wp-content/uploads/digital-library/nordicdigra2014_submission_8.pdf, 21.4.2017.

Behrmann, M., Point, J. C., Noyons, M., \& Robertson, E. (2013). The future of the European mobile game ecosystem. Final findings of the mobile game arch research project, EU FP7/2007-2013/n 288632, http://www.mobilegamearch.eu/wp-content/uploads/2013/09/MGAfinalbrochure.pdf, 21.4.2017

Beyer, A., \& Carl, P. (2004, 2012). Einführung in die Medienökonomie. UVK.

Bracher, K. D. (1975, 1983). Die Krise Europas, Frankfurt, Ullstein. 
Caves, R. (2000). Creative industries. Harvard University Press.

Ferrari, E., Lessiter, J., Freeman, J., \& Dumbreck, P. (2010). Users and uses of games and community activities. Deliverable 2.1 $\begin{array}{lllll}\text { of } & \text { CNG } & \text { Project, } & \text { EU }\end{array}$ http://www.cng-project.eu/documents/CNG\%20D2.1\%20Users\%20and\%20Uses-games\%20community\%20activities\%20v1 0.pdf, 22.4.2017

Rauda, C. (2013). Recht der Computerspiele. Beck.

Renner, T. (2004). Kinder, der Tod ist gar nicht so schlimm. Campus.

Schultheiss, D. (2007). Long-term motivations to play MMOGs: A longitudinal study on motivations, experience and behavior. DiGRA.

http://s3.amazonaws.com/academia.edu.documents/3448846/045.pdf?AWSAccessKeyId=AKIAIWOWYYGZ2Y53UL3A\& Expires=1492875181\&Signature=B\%2FfTdVT0Wd\%2F8vrLi5k9xl1\%2BnXYc\%3D\&response-content-disposition=inline \%3B\%20filename\%3DLong-term_motivations_to_play_MMOGs_A_lo.pdf, 22.4.2017

Talleyrand-Perigord, C. M. D. (1891). Mémoires du Prince de Talleyrand: La Confession de Talleyrand. V.1-5, A de Broglie, Calmann Lévy.

Wi, J. H. (2009). Innovation and strategy of online games. Imperial College Press. 